\title{
The Rodent Models of Dyskinesia and Their Behavioral Assessment
}

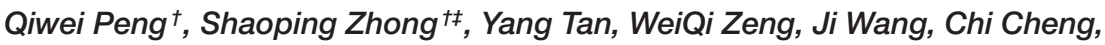 \\ Xiaoman Yang, Yi Wu, Xuebing Cao and Yan $\mathrm{Xu}$ *
}

Department of Neurology, Tongji Medical College, Union Hospital, Huazhong University of Science and Technology, Wuhan, China

\section{OPEN ACCESS}

Edited by:

Alain Kaelin-Lang,

Neurocenter of Southern Switzerland

(NSI), Switzerland

Reviewed by:

Barbara Picconi,

Università Telematica San

Raffaele, Italy

M. Angela Cenci,

Lund University, Sweden

${ }^{*}$ Correspondence:

Yan Xu

xuyanwxf@126.com

†These authors have contributed equally to this work as co-first authors

¥Present address: Shaoping Zhong, Department of Neurology, Zhongshan Hospital, Fudan University, Shanghai,

China

Specialty section

This article was submitted to Movement Disorders,

a section of the journal

Frontiers in Neurology

Received: 12 May 2019 Accepted: 09 September 2019 Published: 11 October 2019

Citation:

Peng Q, Zhong S, Tan Y, Zeng W, Wang J, Cheng $C$, Yang $X, W U$ Y, Cao $X$ and $X u Y$ (2019) The Rodent Models of Dyskinesia and Their

Behavioral Assessment.

Front. Neurol. 10:1016 doi: 10.3389/fneur.2019.01016
Dyskinesia, a major motor complication resulting from dopamine replacement treatment, manifests as involuntary hyperkinetic or dystonic movements. This condition poses a challenge to the treatment of Parkinson's disease. So far, several behavioral models based on rodent with dyskinesia have been established. These models have provided an important platform for evaluating the curative effect of drugs at the preclinical research level over the past two decades. However, there are differences in the modeling and behavioral testing procedures among various laboratories that adversely affect the rat and mouse models as credible experimental tools in this field. This article systematically reviews the history, the pros and cons, and the controversies surrounding rodent models of dyskinesia as well as their behavioral assessment protocols. A summary of factors that influence the behavioral assessment in the rodent dyskinesia models is also presented, including the degree of dopamine denervation, stereotaxic lesion sites, drug regimen, monitoring styles, priming effect, and individual and strain differences. Besides, recent breakthroughs like the genetic mouse models and the bilateral intoxication models for dyskinesia are also discussed.

Keywords: dyskinesia, disease models, behavior rating scale, Parkinson's disease, Levodopa, abnormal involuntary movements, rodent

\section{INTRODUCTION}

Dopamine (DA) replacement therapy with levodopa (L-DOPA) is the most effective pharmacotherapy for motor symptoms of Parkinson's disease (PD). However, prolonged L-DOPA use inevitably leads to complications such as motor fluctuations (i.e., on-off fluctuations and wearing-off phenomenon) and dyskinesia. As the earliest and the most common complication, L-DOPA-induced dyskinesia (LID) occurs in half of the patients undergoing treatment for 5 years $(1,2)$. Dyskinesia is defined as abnormal involuntary movements characterized by hyperkinetic movements or dystonic features (3). This occurs mostly at the maximal L-DOPA plasma level (peak-dose dyskinesia) and less commonly at the initial or the late phase of drug use, or both (diphasic dyskinesia) (4). It should be noted that dyskinesia can also be induced by other DA agonists or dopaminergic neuron transplant (viz., graft-induced dyskinesia, GID) (5), but LID is the most classical type. Although much has been learnt about the risk factors of dyskinesia (i.e., the onset age of PD, disease severity, L-DOPA dosage, and pulsatile administration) (1), its exact molecular mechanisms remain unresolved and there is no effective treatment for $\operatorname{PD}(6,7)$. 
Animal model plays an important role in therapeutics research. The 1-methyl-4-phenyl-1,2,3,6-tetrahydropyridine (MPTP)-lesioned non-human primate was the first model of LID. It provides an accurate replication of motor features of human dyskinesia, but the use of this model is largely limited by adverse factors like non-unified methodological criteria and high cost $(8,9)$. Given the advantages of time- and cost-effectiveness and the ease of genetic manipulation, several rodent dyskinesia models have been developed since the 1990s. However, only few dyskinesia assessment protocols have been validated based on available clinical agents known to have efficacy on LID. In this paper, we discuss the recent advances in modeling dyskinesia in rodents (mainly in unilateral 6-OHDA-lesioned rodents) and analyze the pros and cons of different dyskinesia assessment protocols. We further discuss the major disputes and factors influencing the assessments procedures and the recent advances in the methods used to establish rodent dyskinesia models. This review aims to provide an application framework of the past and present rodent models of dyskinesia to help researchers using the available animal models and behavioral assessment protocols to obtain reliable findings.

\section{THE DEVELOPMENT OF RODENT MODELS OF DYSKINESIA}

\section{6-OHDA Rat Model}

The unilateral 6-OHDA-lesioned rat model is a classical model for $\mathrm{PD}$ motor symptoms that was first introduced in the 1960 s, soon after which drug-induced involuntary rotation was described in this model $(10,11)$. Due to the lack of typical motor impairments observed in human parkinsonism, i.e., bradykinesia, rigidity, and rest tremor, rotation has long become the only behavioral output in unilaterally 6-OHDA-lesioned rats and is used to test parkinsonian disability and modeling the response to DA replacement therapy $(12,13)$.

In the 1970s, Creese and Iversen observed a series of stereotypy responses induced by amphetamine in DA denervated rats and established a rough rating scale where the numbers stand for the presence or absence of a certain response state, i.e., sniffing, licking, and gnawing (14). Since then, the term stereotypy was used to refer to the dopaminergic drug-induced abnormal response in parkinsonian rats $(15,16)$. However, stereotypy did not fit specific symptomatic analogs in human patients, and its dyskinetic predictive value has been doubted by some scholars (17) as stereotyped behavior may also be induced among normal rats by over-stimulation of the DA system (18).

In the 1990s, scholars found that changes in rotation behavior over time may be a useful model for motor fluctuations (19).

Abbreviations: PD, Parkinson's disease; DA, dopamine; L-DOPA, levodopa; LID, L-DOPA-induced dyskinesia; GID, graft-induced dyskinesia; MPTP, 1methyl-4-phenyl-1,2,3,6-tetrahydropyridine; 6-OHDA, 6-hydroxydopamine; AIM, abnormal involuntary movements; MFB, medial forebrain bundle; PPE$A$, preproenkephalin-A; PPE-B, preproenkephalin-B; GAD, glutamic acid decarboxylase; AADC, aromatic amino acid decarboxylase; CNS, central nervous system; GABA, $\gamma$-aminobutyric acid; ERK1/2, extracellular regulated kinase 1 and 2; DARPP-32, phosphoprotein of $32 \mathrm{kDa}$; m-TOR, mammalian target of rapamycin; GRF1, guanine nucleotide exchange.
Before long, Henry et al. introduced a rotation sensitization model for measuring dyskinesia in rats (20). Actually, response sensitization, viz., a gradual increase in rotation or stereotypy response to repeated administration of DA agonists, has been reported in unilateral 6-OHDA-lesioned rats earlier before the 1980s $(21,22)$, but it was Henry who first linked this abnormal response with dyskinesia since LID also shares a gradual increasing severity over time in the non-human primate models. Although disputed, the theory has been modified and used to investigate the pharmacological efficacy of antidyskinetic agents by some laboratories $(23,24)$.

Elsewhere, Cenci and colleagues first observed and defined the abnormal involuntary movements (AIMs) in rats after a 2- to 3-week administration of L-DOPA. The features matched with the dyskinetic manifestations of PD patients and non-human primate models (25). Rat AIMs were classified into four subtypes according to the body parts involved, i.e., rotational locomotion, axial torsion, limb movements, and orolingual stereotypies, and each subtype was scored 0-4 separately in accordance with the corresponding time/monitoring period during which the body part was affected (25). However, rotational locomotion differs from the other three subtypes (collectively called ALO AIMs or Body AIMs) due to its unique properties, which are discussed in detail under the subsection "Controversies around the assessment of rodent dyskinesia." Later on, some modifications were performed on this scale, e.g., addition of amplitude scores for limb and axial AIMs to increase scoring accuracy (26), but such amplitude scores are too complicated to be applied in majority of studies. Cenci's rating scale has since been well-accepted in dyskinesia studies since it was validated by high-quality pharmacological trials and LID molecular markers' tests (25, 27-29). Although detailed rating rules, e.g., the turns and intervals of rating, were constantly revised by subsequent groups (30-32), the framework of this scale remains unchanged.

Similarly, Steece-Collier et al. developed an independent rating scale for rat dyskinesia $(33,34)$. This scale had more subcategories of dyskinetic movements, i.e., neck postural dysfunction, trunk dystonia, forelimb dystonia, hindlimb dystonia, contralateral forepaw dyskinesia, orolingual stereotypy, and forelimb-facial stereotypy. During the rating session, scores of each item are graded separately based on the intensity and frequency and then multiplied, named as severity scores. The total LID score is calculated by the severity scores. SteeceCollier's scale is mainly used for evaluating LID in mesencephalic dopaminergic neuron graft rats (34-36) and also for GID rating (37).

Thus, far, Henry's, Cenci's, and Steece-Collier's protocols have been used for the behavioral assessment of dyskinesia in rats by other researchers with modifications $(24,30,38,39)$. Being the first model to quantitatively record LID in rats, Henry's protocol differs from the other two in many aspects, and its efficiency is controversial as it is not clear whether rotational behavior is a manifestation of rodent dyskinesia (40). Despite similarities in the rating rules, there are remarkable differences in the rating items and monitoring styles between Cenci's and SteeceCollier's protocols (Table 1). Whereas, Cenci's scale is designed to avoid measuring stereotyped behaviors (orolingual AIM 
TABLE 1 | Current options used to induce and evaluate LID in unilateral 6-OHDA-lesioned rat models.

\begin{tabular}{|c|c|c|c|}
\hline & $\begin{array}{l}\text { Henry's protocol } \\
\text { (Rotational sensitization) }\end{array}$ & $\begin{array}{l}\text { Cenci's protocol } \\
\text { (AIMs rating scale) }\end{array}$ & Steece-Collier's protocol \\
\hline \multicolumn{4}{|l|}{ MODELING PROCEDURES } \\
\hline Lesion sites & MFB & MFB/striatum & MFB \\
\hline Screening & Spontaneous rotation & $\begin{array}{l}\text { Amphetamine-induced } \\
\text { rotation }\end{array}$ & $\begin{array}{l}\text { Amphetamine-induced } \\
\text { rotation }\end{array}$ \\
\hline \multirow[t]{2}{*}{ LID inducing (drugs and dosage) } & Methyl L-DOPA 6.5 mg/kg/day & Methyl L-DOPA 6 mg/kg/day & Methyl L-DOPA 50 mg/kg/day \\
\hline & Benserazide 25 mg/kg/day & Benserazide 25 mg/kg/day & Carbidopa 5 mg/kg/day \\
\hline \multicolumn{4}{|l|}{ LID ASSESSMENT } \\
\hline Rating targets & Rotational turns & $\begin{array}{l}\text { The presenting time of } \\
\text { locomotive, axial, limb, } \\
\text { and orolingual AIMs }\end{array}$ & $\begin{array}{l}\text { The presenting time and the intensity of } \\
\text { dyskinetic movements in different parts of } \\
\text { the body }\end{array}$ \\
\hline Patterns of movements scored & Contralateral rotation & $\begin{array}{l}\text { Rotational locomotion, axial torsion, limb } \\
\text { movements, and orolingual stereotypies }\end{array}$ & $\begin{array}{l}\text { Clasping of forepaw, twisting of axial } \\
\text { musculature, torsional movements } \\
\text { beginning in the neck region, and twisting } \\
\text { of limbs. }\end{array}$ \\
\hline Monitoring styles & $\begin{array}{l}\text { A consecutive 120-min } \\
\text { monitoring }\end{array}$ & $\begin{array}{l}\text { A disconnected } 180-\text { min } \\
\text { monitoring with } 9 \text { turns of } \\
\text { rating, and each rating } \\
\text { session lasts } 1 \text { min }\end{array}$ & $\begin{array}{l}\text { A single-point 2-min rating } \\
30 \text { min after the } \\
\text { administration of L-DOPA }\end{array}$ \\
\hline Rating styles & Automated rotometry & Human observation & Human observation \\
\hline Pros & $\begin{array}{l}\text { Time-effective } \\
\text { an objective measuring } \\
\text { with high inter-rater } \\
\text { consistency }\end{array}$ & $\begin{array}{l}\text { Good validation in } \\
\text { pharmacological and } \\
\text { biomarker's tests }\end{array}$ & $\begin{array}{l}\text { The precise recording of } \\
\text { dyskinetic movements }\end{array}$ \\
\hline \multirow[t]{2}{*}{ Cons } & $\begin{array}{l}\text { Not supported by } \\
\text { pharmacological validation }\end{array}$ & $\begin{array}{l}\text { Relatively poor inter-rater } \\
\text { reliability }\end{array}$ & $\begin{array}{l}\text { Lack of pharmacological } \\
\text { validation }\end{array}$ \\
\hline & $\begin{array}{l}\text { The predictive value of } \\
\text { rotational sensitization is controversial }\end{array}$ & & $\begin{array}{l}\text { Single-point sampling at the peak time } \\
\text { cannot cover the whole time-action curve } \\
\text { of an agent }\end{array}$ \\
\hline
\end{tabular}

excepted), Steece-Collier's scale is a hybrid of both dyskinetic and stereotypy-like movements scoring (41). The fact that more stereotypic movements and less dystonic features occur in postgrafting rats might account for this deference in designing (34), as the latter was initially designed for dopaminergic neuron transplantation-related studies. In their attempt to distinguish between choreiform and dystonic movements, Steece-Collier's scale is similar to that used in the clinic and seems to be more accurate in recording of rodent dyskinesia, but a single-point scoring only at the peak-dose period was considered a limitation.

\section{6-OHDA Mouse Model}

MPTP injection is the classic approach used to induce PD in mice. However, MPTP mice exhibit a prominent capacity for motor function recovery instead of persistent dysfunction; thus, they are suitable for molecular and cellular mechanisms studies rather than studying the symptomatology of PD (42). Indeed, some scholars have attempted to induce LID in MPTP mice with a high dose of L-DOPA and found that such dose causes few dyskinetic subtypes, unlike that observed in the non-human primate model or 6-OHDA-lesioned rat model (43). The study of LID in mice lagged far behind that in rats. It was the case until unilateral 6-OHDA-lesioned mice were introduced by Cenci's group and a similar AIM rating scale for mice was built up in 2004 (44). The advantage of the 6-OHDA lesion procedure lies in its stable and duplicable damage to the nigrostriatal DA neurons, besides its high predictability during the time course of DA degeneration (8). Compared with the rat, mouse AIMs are more rapid, have a more simplified repertoire, and present more prominent rotational locomotion with less dystonic features, i.e., axial AIMs $(44,45)$. High postoperative mortality used to be a major obstacle to the development of mouse models, especially those lesioned in the medial forebrain bundle (MFB), but recent progress in surgical procedures and postoperative support have improved this situation $(46,47)$.

\section{VALIDATION OF RODENT MODELS}

Animal models play an irreplaceable role in the search of new medications for LID. It is important for a model to be validated. There are two main aspects of validity referred to here: predictive validity and construct validity. Predictive validity reflects how well the animal model imitates humans in response to experimental manipulation; thus, naturally it can be probed by testing the model's response to the effects of pharmacological agents known to alleviate or aggravate LID in the clinic. While construct validity examines whether the test performance is based on the actual neurobiological mechanisms underlying 
the disease. Accordingly, this is determined by quantifying dyskinesia-associated molecular markers in the animal model (48). Henry's group first compared the rotational behavior in rats caused by L-DOPA and bromocriptine (a DA agonist known to present low dyskinesiogenic potential when clinically used for PD treatment). They pronounced that there was no significant sensitization in the bromocriptine group (39). However, such a conclusion was met with strong criticisms $(28,49)$. Cenci's protocols have been tested by other agonists with low dyskinesiogenic potential including quinpirole, pramipexole, ropinirole, and bromocriptine, etc. in rats $(13,28,50)$ and mice (45). These tests highlighted a good predictive validity of the rodent AIMs in line with the measures of dyskinesia that are used in both the clinic and non-human primate models. Moreover, L-DOPA-induced ALO AIMs could be ameliorated by clinically confirmed antidyskinetic compounds including amantadine, clozapine, and yohimbine in rats $(28,29)$, which further supports AIM scores (locomotive AIM excepted) as a reliable assessment tool for dyskinesia. Although few pharmacological validations for Steece-Collier's protocol have been reported, a good correlation has been recently demonstrated between this protocol and that developed by Cenci (41).

It was previously demonstrated that striatal mRNA's level of opioid precursors and related proteins, i.e., preproenkephalinA (PPE-A), preproenkephalin-B (PPE-B), the $67-\mathrm{kDa}$ isoform of glutamic acid decarboxylase (GAD67), closely, if not specifically, correlated with dyskinesia expression in primate PD models (7), which were also the postsynaptic markers of basal ganglia output pathways. To test the construct validity of Henry's protocol, several groups have reported upregulation of PPE-A, PPE-B (39), or their precursor Pdyn (24) mRNA level in response to rotational sensitization in rats treated repeatedly with L-DOPA; however, the lack of subgroup analysis in these studies made it difficult to confirm that the upregulation of these markers is a specific response to rotation behavior other than the general effects of drug treatment. In Cenci's protocol, better experimental controls were designed, which highlighted a linear positive correlation between ALO AIM scores and the expression level of these molecules in rats (25-27) and mice $(44,51)$. Also using Cenci's protocol, a highly interactive and positive correlation was found between the expression level of transcription factor FosB/ $\Delta$ FosB and dyskinesia severity in rats (27) and mice (44), which was later confirmed to occur in PD patients $(52,53)$ and non-human primate models $(54,55)$. Overall, these studies demonstrate the validity of Cenci's protocol. A similar validation for Steece-Collier's protocol has also been done, but only in a few reports $(34,35)$.

\section{CONTROVERSIES AROUND THE ASSESSMENT OF RODENT DYSKINESIA}

\section{The Predictive Value of the Rotation}

Few behaviors are more impressive than drug-induced rotation in hemiparkinsonian rodents. DA agonists induce contralateral rotation, while agents that increase DA levels, i.e., amphetamine and amantadine, cause ipsilateral rotation. The physiological mechanism of this specific behavior has not been completely elucidated $(28,56)$. However, the dominant DA-dependent hypothesis advocates that circling is the result of a bilateral dopaminergic imbalance in the striatum and animals always tend to rotate toward the side with lower striatal dopaminergic activity (57).

The interpretation of rotation has always been the focus of debate. For a long time, the intensity of rotation was regarded to be a correlative index of the degree of neurotoxininduced DA denervation for screening well-lesioned animals, as well as an indicator for evaluating the anti-akinetic efficiency of antiparkinsonian drugs $(12,58,59)$. An inherent contradiction of this theory lies in the following reasoning: if the intensity of rotation is equivalent to the therapeutic effects, then the sensitization of rotational behavior should naturally be interpreted as an enhanced therapeutic action, which is apparently inconsistent with the clinical fact that the efficacy of LDOPA always decreases gradually as the medication persists (12). Moreover, L-DOPA-induced rotation is a purposeless movement that is poorly correlated with the improvement of motor function as determined by cylinder test or rotarod test $(28,60)$, as sensitive measures of motor impairments in hemiparkinsonian rodents. Presently, majority of studies have reached a consensus that the measure of rotation should not be included in the AIM score $(29,49,61,62)$, and the shortened duration of rotation response should be viewed as a behavioral index of "wearing-off" like phenomenon $(59,61)$, but the behavioral significance of rotation requires further clarification.

\section{Environmental Interference}

Environmental factors, mainly the test apparatus in which dyskinesia and rotation measures are performed, have not been considered as a source of interference. Various designs and sizes of test apparatus are employed in different laboratories, including hemispheric bowl (i.e., automated rotometry), rectangular boxes (i.e., rearing cages), and cylinder containers. Pinna et al. first reported that a more prominent sensitization of rotational behavior was induced when rats were tested in the hemispheric apparatus compared with rectangular boxes (63). However, this idea was challenged by other scholars $(29,41)$ as different counting procedures, i.e., automated rotometry and visual observation, were used in this case. Conversely, it was found that all AIM scores, Steece-Collier's scores, and the number of rotation turns in the Cenci model were not significantly different between round cylinders and square boxes (41).

Nevertheless, it should be noted that a number of previous studies that confirmed the environment-dependent behavioral response to DA agonists were performed in non-parkinsonian rodents (64-66). According to our observation (unpublished), motor response to L-DOPA is always disturbed or suspended when the rat moves to the corners of a rectangular box, and more dyskinetic features but less rotation behavior are presented in an enclosed and smaller container compared with the open field. A possible explanation for this difference might be that the container's walls facilitate a bipedal standing position in rats, which is associated with ALO AIMs (67). Based on these clues, it is reasonable to speculate that the test environment influences 
the rodent dyskinesia assessment; however, further supporting evidence is required to confirm this concept.

\section{FACTORS THAT INFLUENCE DYSKINESIA ASSESSMENT IN RODENTS}

\section{DA Denervation}

Numerous studies have demonstrated a positive but nonlinear correlation between AIM scores and the extent of DA denervation in rats $(26,27,67)$ and mice $(44,45)$ by quantifying spared nigral DA neurons (determined by tyrosine hydroxylase immunohistochemistry) and/or striatal DA fibers (determined by DA transporter autoradiography). These studies found that a residual DA innervation below a critical, threshold value is a necessary prerequisite for animals to develop AIMs. In rats, it has been reported that $<10 \%$ of DA cell sparing is needed for overt ALO AIMs, while a stricter $<5 \%$ DA cell sparing is required for locomotive AIM (26). This is in line with the mainstream findings that DA denervation is a necessary but not sufficient condition for the development of dyskinesia in patients (68).

\section{Animal Individual Differences}

Similar to human dyskinesia, hemiparkinsonian rodents exhibit significant differences in latency, severity, and subtypes of AIMs across individuals, although these features are relatively constant in one animal $(27,67)$. This cannot be only interpreted by the degree of DA denervation as AIM scores show a dispersed distribution even among rats with most severe denervation. Although the mechanisms are not fully understood, it has been proposed that the presence of non-dyskinetic animals and a high inter-individual variability in AIMs severity might contribute to understanding the factors that promote human dyskinesia $(8,69)$.

\section{6-OHDA Lesion Sites}

For nigrostriatal lesion, two main intracranial injection sites are used: MFB and striatum. The classical MFB model produces a fast $(<3-4$ days) and severe (usually $<20 \%$ residual innervation) DA depletion that imitates the advanced stage of $\mathrm{PD}$, while striatal lesion leads to a protracted and moderate retrograde degeneration (1-3 weeks) more similar to that seen in parkinsonian patients; for a review, see (42). A study by Winkler et al. compared dyskinetic features between these two models and found an overall lower incidence, less severity, and different topographic distribution of AIMs in the latter model under the same L-DOPA dosage (26). Importantly, there was no locomotive AIM (or rotation) in intrastriatally lesioned rats. This may be ascribed to the fact that locomotion in rodents is mediated by DA fibers in the medial subregion of striatum, and intrastriatal administration of 6-OHDA triggers a focal destruction only in the ventrolateral striatum, but not in the medial striatum. In contrast, the MFB lesion damages the DA fibers in the whole striatum $(26,27)$. Correspondingly, intrastriatally lesioned mice were less likely to develop dyskinesia compared to MFB-lesioned ones, but there was no difference in the representation of AIM subtypes (44). It was proposed that different brain sizes might account for this inter-species variation.
An unusual characteristic of striatum-lesioned mice is the decline of AIM severity after a few weeks of L-DOPA treatment (45). The mechanism for this observation is poorly understood, but a postsynaptic hypothesis, viz., the desensitization of postsynaptic D1 receptor (45), and the shortening of the motor response duration to L-DOPA $(19,45,70)$ similar to the "wearing-off" phenomenon of one of the late complications of drug treatment for PD may account for this.

\section{The Dosage Regimen of L-DOPA and Benserazide}

A dose-dependent relationship has been demonstrated between L-DOPA and the intensity of rotation, rotational sensitization, and AIM scores (49). Given its higher water solubility, L-DOPA methyl ester hydrochloride (methyl L-DOPA) is commonly used in many laboratories instead of ordinary L-DOPA. However, the dose of methyl L-DOPA adopted in previous studies varies from 2.5 to $50 \mathrm{mg} / \mathrm{kg}$, making it challenging to directly compare results between such studies. Cenci and Lundblad proposed 6-10 mg/kg per injection as a standard dosage for rats and MFB-lesioned mice in dyskinesia studies, but a three- to four-fold dosage is required for intrastriatally lesioned mice to yield similar dyskinetic responses (71). It was reported that a standard dose regimen produced a pronounced interindividual variation of dyskinesia severities, but a high-dose regimen (usually $>25 \mathrm{mg} / \mathrm{kg} /$ day) evoked a more uniform response with rotation in all animals (69). Besides the dosage per injection, administration frequency may also influence animal behaviors. Rodents receiving frequent injections maintained a hyperactive state for a longer time during a day, but application of the dose once or twice per day is recommended to be sufficient for dyskinesia studies (71).

Benserazide, a peripheral inhibitor of aromatic amino acid decarboxylase (AADC), is concomitantly used with L-DOPA to increase its effective concentration in CNS while reducing its peripheral side effects. It has been found that benserazide prolongs the acting time of L-DOPA dose-dependently in rodents (72). According to Cenci's report, when benserazide was applied at a dose of $<8 \mathrm{mg} / \mathrm{kg}$ per day, the duration of L-DOPA action lasted for $100 \mathrm{~min}$, which diminished the AIM scores. In contrast to the fixed ratio of L-DOPA:benserazide, 4:1 in standard clinical preparations, the dosage of benserazide for rodents varies greatly among studies; thus, a dose of 12 to $15 \mathrm{mg} / \mathrm{kg} /$ day has been proposed to be the appropriate regimen for inducing rodent dyskinesia (71).

\section{The Length and Turns of Monitoring}

As mentioned above, a long enough monitoring is important for evaluating the anti-dyskinetic potential of different drugs, especially those with unknown pharmacodynamic profiles. The original version of Cenci's protocol adopted a 180-min monitoring with nine turns of scoring $(25,27,44)$, but different lengths (such as 60,120,160, and $240 \mathrm{~min}$ ) and turns (2, 4, 8, and 12 , respectively) of monitoring have also been used currently ( 31 , $32,73,74)$. Whatever length is employed, it must be able to cover the whole time-action curve of the agents being investigated. Furthermore, a multiple time-point evaluation has been found to 
be superior to selected peak-time assessment adopted in SteeceCollier's protocol, as some agents, e.g., amantadine, may reduce dyskinesia severity at peak time, but prolong the duration of motor dysfunction (41).

\section{Priming Effect}

Priming refers to the phenomenon in which a single or repeated exposure to specific DA agonists would lead to a longlasting enhancement of locomotor and stereotypic behaviors elicited by the subsequent DA agonist challenge (75). A study showed that twice administration of apomorphine 1 month earlier would remarkably promote rotation behavior and AIMs during the subsequent chronic DA replacement therapy, inducing not only a higher degree of turning and AIM scores but also an earlier emergence of their peak value, which occurred on the first rating day (13). Thus, the priming effect should be seriously taken into consideration, as dopaminergic drugs, e.g., apomorphine, is commonly used for screening well-lesioned animals. Alternative drug-free tests such as the cylinder test have been found to be effective in avoiding such interference (71).

\section{Strain Differences}

Unlike MPTP, the sensitivity to 6-OHDA among different strains of rats and mice are relatively stable (42); thus, strain differences are always not considered in rodent dyskinesia studies. So far, almost all published studies were carried out in Sprague Dawley rats, Wistar rats, or C57BL6 mice. Thiele et al. compared the rotation behavior and AIMs of pure FVB and FVB/C57BL6 mice following a chronic L-DOPA treatment. They observed that the latter were more sensitive to develop dyskinetic behaviors under the same dosing regimen (76). No other strain comparisons have been reported so far, but such a latent interstrain difference should be considered as different strains of transgenic mice might be used for dyskinesia studies in the future.

\section{CURRENT USAGE AND ADVANCES IN THE USE OF RODENTS IN DYSKINESIA STUDIES}

Given the developments witnessed in the past two decades, the use of rodents as useful models for dyskinesia has gradually become mainstream in academia $(8,69)$. Cenci's protocol has become the most widely accepted option for evaluating dyskinesia in 6-OHDA-lesioned rodents. On the basis of this protocol, numerous pharmacological trials have led to the discoveries of several promising therapeutic targets in recent years, including the GABA system (77-79), the serotonin system (80-84), adenosine receptors (85-88), opioid receptors (89-92), neuronal nitric oxide synthase inhibition (93), $\beta_{2}$ nicotinic receptors (94-98), and cation channels $(99,100)$. Confidence in the application of rodent models has been further boosted by the findings that the GABA system and serotonin system translate quite well when these agents are applied in non-human primate models and clinical trials (8). Otherwise, due to the ease of genetic engineering (both knock-in and knock-outs), the mouse has become the standard model for studying molecular pathways of dyskinesia. This model has led to the discovery that the ERK1/2-DARPP32-mTOR and Ras-GRF1 signal pathways play important roles in the development of LID (51, 55, 101-103). Previous studies have shown that changes in synaptic plasticity influence the pathogenesis of dyskinesia $(104,105)$. It has been demonstrated that bidirectional synaptic plasticity exists in the cortical striatum of normal rats, including long-term potentiation (LTP) and long-term depression (LTD). This bidirectional synaptic plasticity is essential in maintaining stable motor function (106). For LID rats, the indirect pathway is only characterized by LTD, while the direct pathway is characterized by LTP (107), which leads to the clinical manifestation of dyskinesia. In addition, many therapeutic approaches targeted at pathways such as mTOR pathway $(108,109)$, Ras-ERK signaling (110, 111), M4 muscarinic receptor signaling (107), and metabotropic glutamate receptors $(112,113)$ have shown high potential in alleviating LID in rats. In recent years, multichannel electrophysiological recording technology has enabled synchronous observation and recording of LFP, spike signals, and behavior in multiple brain regions, which paves the way for a deeper understanding of the mechanism of abnormal neural loops in PD and dyskinesia. The $\beta$-oscillation associated with motor inhibition in the cortical-basal ganglia circuit $(114,115)$ and the gamma oscillation associated with dyskinesia $(116,117)$ have been confirmed in various animal models such as rats, mice, non-human primates, and human experiments. Although the mechanisms of the electrophysiological abnormalities are not fully known, the relationship between electrophysiological indicators and pathological status provides new avenues for evaluating the efficacy of drugs on dyskinesia.

Over the past 10 years, a number of discoveries have been made, which have expanded our understanding into the role of rodent models in LID studies. Paille et al. established the first bilateral 6-OHDA-lesioned rat model for dyskinesia study, although this model was characterized by unilateral AIMs (118). Interestingly, a study reported that asymmetric severity of AIMs was induced in the left, right, and inverse sequential bilateral lesioned rats (119). This may have a profound effect on rodent LID models if it is proven to be correct in further studies. Although tremendous progress has been made in developing genetic animal models of PD in recent years, there are still many challenges affecting behavioral research. One of the key limitations is that these models cannot reproduce the degeneration of dopaminergic neurons observed in PD patients. For mouse models used to study gene overexpression involving some familial PD forms, such as $\alpha$-synuclein and leucine-rich repeat kinase 2 , since they do not experience dopaminergic cell loss, LID cannot be induced with levodopa treatment (120), and there is currently no single PD animal model that perfectly replicates all the core features of PD (121). Nevertheless, this model still plays an important role in exploring the molecular mechanisms of early pathological changes in PD. It has been reported that RGS9 knockout mice are induced to dyskinesia when subsequently activating D2-like dopamine receptors 
(DRs) following inhibition of dopaminergic transmission (122). $\mathrm{Pitx} 3^{\mathrm{ak} / \mathrm{ak}}$ mice, or aphakia mice, are established by deletion of the Pitx3 promoter region. Aphakia mice display a spontaneous recessive phenotype characterized by lack of lens in the small eyes (123) and during development. In this mice, both sides of the cerebral hemisphere lack the nigrostriatal DA projection and hence are more likely to develop LID. In 6-OHDA and other drug-induced PD mouse models, it is not easy to achieve bilateral DA depletion without excessive mortality (124). Cao et al. (125) injected a virus vector carrying $\triangle \mathrm{FosB} c \mathrm{CNA}$ into the injured striatum of rats, and Feyder et al. (126) developed a PD model of mitogen and stress-activated kinase 1 knockout mice (MSK1KO) and $\Delta$ FosB- or $\Delta$ cJun-overexpressing transgenic mice with 6OHDA. In both studies, chronic L-DOPA treatment successfully induced LID.

\section{CONCLUSIONS}

The development of unilateral 6-OHDA-lesioned rodent models and the establishment of corresponding behavioral assessment protocols have greatly promoted the research of dyskinesia over the past two decades. This has led to the discovery of several novel therapeutic agents to control the intractable complications advanced PD. In spite of the controversies surrounding the behavioral assessment in these models, rodent models are still powerful and cost-effective tools in dyskinesia studies. In order to properly assess abnormal involuntary movement of PD

\section{REFERENCES}

1. Manson A, Stirpe P, Schrag A. Levodopa-induced-dyskinesias clinical features, incidence, risk factors, management and impact on quality of life. J Parkinson's Dis. (2012) 2:189-98. doi: 10.3233/JPD-2012-120103

2. Rajput AH, Fenton ME, Birdi S, Macaulay R, George D, Rozdilsky B, et al. Clinical-pathological study of levodopa complications. Mov Disord. (2002) 17:289-96. doi: 10.1002/mds.10031

3. Calabresi P, Filippo MD, Ghiglieri V, Tambasco N, Picconi B. Levodopa-induced dyskinesias in patients with Parkinson's disease: Filling the bench-to-bedside gap. Lancet Neurol. (2010) 9:1106-17. doi: 10.1016/S1474-4422(10)70218-0

4. Kalia LV, Lang AE. Parkinson's disease. Lancet. (2015) 386:896-912. doi: 10.1016/S0140-6736(14)61393-3

5. Lane EL, Smith GA. Understanding graft-induced dyskinesia. Regen Med. (2010) 5:787-97. doi: $10.2217 /$ rme.10.42

6. Cenci MA. L-DOPA-induced dyskinesia: Cellular mechanisms and approaches to treatment. Parkinsonism Relat Disord. (2007) 13:S263-7. doi: 10.1016/S1353-8020(08)70014-2

7. Jenner P. Molecular mechanisms of L-DOPA-induced dyskinesia. Nat Rev Neurosci. (2008) 9:665-77. doi: 10.1038/nrn2471

8. Iderberg H, Francardo V, Pioli EY. Animal models of L-DOPA-induced dyskinesia: An update on the current options. Neuroscience. (2012) 211:13-27. doi: 10.1016/j.neuroscience.2012.03.023

9. Potts LF, Wu H, Singh A, Marcilla I, Luquin MR, Papa SM. Modeling Parkinson's disease in monkeys for translational studies, a critical analysis. Exp Neurol. (2014) 256:133-43. doi: 10.1016/j.expneurol.2013.09.014

10. Ungerstedt U. 6-Hydroxy-dopamine induced degeneration of central monoamine neurons. Eur J Pharmacol. (1968) 5:107-10. doi: 10.1016/0014-2999(68)90164-7

11. Ungerstedt U. Postsynaptic supersensitivity after 6-hydroxy-dopamine induced degeneration of the nigro-striatal dopamine system. Acta Physiol Scand Suppl. (1971) 367:69-93. doi: 10.1111/j.1365-201X.1971.tb11000.x rodents and to accurately conduct related mechanisms and drug development studies, these behavioral assessment methods and rating scales need to be used rationally.

\section{AUTHOR CONTRIBUTIONS}

QP, SZ, YT, WZ, JW, CC, YW, and XY reviewed the literature and drafted the manuscript. $\mathrm{YX}$ and $\mathrm{XC}$ revised and proofread the manuscript. All authors read and approved the final manuscript.

\section{FUNDING}

This work was supported by the National Natural Science Foundation of China (NSFC Project No. 81671108 and No. 81873734).

\section{ACKNOWLEDGMENTS}

We are grateful to the Undergraduate Training Programs for Innovation and Entrepreneurship of Huazhong University of Science and Technology for providing the necessary support for this work. We thank Prof. Stella M. Papa for the kind and constructive suggestions during manuscript writing. We also thank Guiqin Chen, $\mathrm{PhD}$, for advice on the manuscript editing, all of whom did not participate in the analysis or writing of this paper.

12. Konitsiotis S, Tsironis C. Levodopa-induced dyskinesia and rotational behavior in hemiparkinsonian rats: Independent features or components of the same phenomenon? Behav Brain Res. (2006) 170:337-41. doi: 10.1016/j.bbr.2006.02.030

13. Delfino MA, Stefano AV, Ferrario JE, Taravini IR, Murer MG, Gershanik OS. Behavioral sensitization to different dopamine agonists in a parkinsonian rodent model of drug-induced dyskinesias. Behav Brain Res. (2004) 152:297-306. doi: 10.1016/j.bbr.2003.10.009

14. Creese I, Iversen SD. The pharmacological and anatomical substrates of the amphetamine response in the rat. Brain Res. (1975) 83:419-36. doi: 10.1016/0006-8993(75)90834-3

15. Lindner MD, Plone MA, Francis JM, Emerich DF. Validation of a rodent model of Parkinson's Disease: Evidence of a therapeutic window for oral Sinemet. Brain Res Bull. (1996) 39:367-72. doi: 10.1016/0361-9230(96)00027-5

16. Mura A, Jackson D, Manley MS, Young SJ, Groves PM. Aromatic L-amino acid decarboxylase immunoreactive cells in the rat striatum: a possible site for the conversion of exogenous L-DOPA to dopamine. Brain Res. (1995) 704:51-60. doi: 10.1016/0006-8993(95)01104-8

17. Cenci MA, Whishaw IQ, Schallert T. Animal models of neurological deficits: how relevant is the rat? Nat Rev Neurosci. (2002) 3:574-9. doi: 10.1038/nrn877

18. Segal DS, Mandell AJ. Long-term administration of d-amphetamine: progressive augmentation of motor activity and stereotypy. Pharmacol Biochem Behav. (1974) 2:249-55. doi: 10.1016/0091-3057(74) 90060-4

19. Papa SM, Engber TM, Kask AM, Chase TN. Motor fluctuations in levodopa treated parkinsonian rats: relation to lesion extent and treatment duration. Brain Res. (1994) 662:69-74. doi: 10.1016/0006-8993(94)90796-X

20. Henry B, Crossman AR, Brotchie JM. Characterization of enhanced behavioral responses to L-DOPA following repeated administration in the 6-hydroxydopamine-lesioned rat model of Parkinson's disease. Exp Neurol. (1998) 151:334-42. doi: 10.1006/exnr.1998.6819 
21. Rouillard C, Bedard PJ, Falardeau P, Dipaolo T. Behavioral and biochemical evidence for a different effect of repeated administration of L-dopa and bromocriptine on denervated versus non-denervated striatal dopamine receptors. Neuropharmacology. (1987) 26:1601-6. doi: 10.1016/0028-3908(87)90008-6

22. Asin KE, Bednarz L, Nikkel A, Perner R. Rotation and striatal c-fos expression after repeated, daily treatment with selective dopamine receptor agonists and levodopa. J Pharmacol Exp Therap. (1995) 273:1483-90.

23. Pinna A, Fenu S, Morelli M. Motor stimulant effects of the adenosine A2A receptor antagonist SCH 58261 do not develop tolerance after repeated treatments in 6-hydroxydopamine-lesioned rats. Synapse. (2001) 39:233-8. doi: 10.1002/1098-2396(20010301)39:3<233::AID-SYN1004>3.0.CO;2-K

24. Carta AR, Pinna A, Cauli O, Morelli M. Differential regulation of GAD67, enkephalin and dynorphin mRNAs by chronic-intermittent L-dopa and A2A receptor blockade plus L-dopa in dopamine-denervated rats. Synapse. (2002) 44:166-74. doi: 10.1002/syn.10066

25. Cenci MA, Lee CS, Bjorklund A. L-DOPA-induced dyskinesia in the rat is associated with striatal overexpression of prodynorphin- and glutamic acid decarboxylase mRNA. Eur J Neurosci. (1998) 10:2694-706. doi: 10.1046/j.1460-9568.1998.00285.x

26. Winkler C, Kirik D, Bjorklund A, Cenci MA. L-DOPA-induced dyskinesia in the intrastriatal 6-hydroxydopamine model of Parkinson's disease: relation to motor and cellular parameters of nigrostriatal function. Neurobiol Dis. (2002) 10:165-86. doi: 10.1006/nbdi.2002.0499

27. Andersson M, Hilbertson A, Cenci MA. Striatal fosB expression is causally linked with L-DOPA-induced abnormal involuntary movements and the associated upregulation of striatal prodynorphin mRNA in a rat model of Parkinson's disease. Neurobiol Dis. (1999) 6:461-74. doi: 10.1006/nbdi.1999.0259

28. Lundblad M, Andersson M, Winkler C, Kirik D, Wierup N, Cenci MA. Pharmacological validation of behavioural measures of akinesia and dyskinesia in a rat model of Parkinson's disease. Eur J Neurosci. (2002) 15:120-32. doi: 10.1046/j.0953-816x.2001.01843.x

29. Dekundy A, Lundblad M, Danysz W, Cenci MA. Modulation of L-DOPAinduced abnormal involuntary movements by clinically tested compounds: further validation of the rat dyskinesia model. Behav Brain Res. (2007) 179:76-89. doi: 10.1016/j.bbr.2007.01.013

30. Zhang H, Ma L, Wang F, Chen J, Zhen X. Chronic SKF83959 induced less severe dyskinesia and attenuated L-DOPA-induced dyskinesia in 6-OHDAlesioned rat model of Parkinson's disease. Neuropharmacology. (2007) 53:125-33. doi: 10.1016/j.neuropharm.2007.04.004

31. Marin C, Bonastre M, Aguilar E, Jimenez A. The metabotropic glutamate receptor antagonist 2-methyl-6-(phenylethynyl) pyridine decreases striatal VGlut2 expression in association with an attenuation of L-DOPA-induced dyskinesias. Synapse. (2011) 65:1080-6. doi: 10.1002/syn.20941

32. Sancesario G, Morrone LA, D'Angelo V, Castelli V, Ferrazzoli D, Sica F, et al. Levodopa-induced dyskinesias are associated with transient downregulation of CAMP and cGMP in the caudate-putamen of hemiparkinsonian rats: reduced synthesis or increased catabolism? Neurochem Int. (2014) 79:44-56. doi: 10.1016/j.neuint.2014.10.004

33. Steece-Collier K, Collier TJ, Danielson PD, Kurlan R, Yurek DM, Sladek JR Jr. Embryonic mesencephalic grafts increase levodopa-induced forelimb hyperkinesia in parkinsonian rats. Mov Disord. (2003) 18:1442-54. doi: $10.1002 / \mathrm{mds} .10588$

34. Maries E, Kordower JH, Chu Y, Collier TJ, Sortwell CE, Olaru E, et al. Focal not widespread grafts induce novel dyskinetic behavior in parkinsonian rats. Neurobiol Dis. (2006) 21:165-80. doi: 10.1016/j.nbd.2005.07.002

35. Steece-Collier K, Soderstrom KE, Collier TJ, Sortwell CE, Maries-Lad E. Effect of levodopa priming on dopamine neuron transplant efficacy and induction of abnormal involuntary movements in parkinsonian rats. J Comp Neurol. (2009) 515:15-30. doi: 10.1002/cne.22037

36. Soderstrom KE, O’Malley JA, Levine ND, Sortwell CE, Collier TJ, SteeceCollier K. Impact of dendritic spine preservation in medium spiny neurons on dopamine graft efficacy and the expression of dyskinesias in parkinsonian rats. Eur J Neurosci. (2010) 31:478-90. doi: 10.1111/j.1460-9568.2010. 07077.x

37. Soderstrom KE, Meredith G, Freeman TB, McGuire SO, Collier TJ, Sortwell $\mathrm{CE}$, et al. The synaptic impact of the host immune response in a parkinsonian allograft rat model: Influence on graft-derived aberrant behaviors. Neurobiol Dis. (2008) 32:229-42. doi: 10.1016/j.nbd.2008.06.018

38. Zhang Y, Meredith GE, Mendoza-Elias N, Rademacher DJ, Tseng KY, Steece-Collier K. Aberrant restoration of spines and their synapses in L-DOPA-induced dyskinesia: Involvement of corticostriatal but not thalamostriatal synapses. J Neurosci. (2013) 33:11655-67. doi: 10.1523/JNEUROSCI.0288-13.2013

39. Henry B, Crossman AR, Brotchie JM. Effect of repeated L-DOPA, bromocriptine, or lisuride administration on preproenkephalin$A$ and preproenkephalin-B mRNA levels in the striatum of the 6-hydroxydopamine-lesioned rat. Exp Neurol. (1999) 155:204-20. doi: 10.1006/exnr.1998.6996

40. Marin C, Rodriguez-Oroz MC, Obeso JA. Motor complications in Parkinson's disease and the clinical significance of rotational behavior in the rat: have we wasted our time? Exp Neurol. (2006) 197:269-74. doi: 10.1016/j.expneurol.2005.11.002

41. Breger LS, Dunnett SB, Lane EL. Comparison of rating scales used to evaluate L-DOPA-induced dyskinesia in the 6-OHDA lesioned rat. Neurobiol Dis. (2013) 50:142-50. doi: 10.1016/j.nbd.2012.10.013

42. Bove J, Perier C. Neurotoxin-based models of Parkinson's disease. Neuroscience. (2012) 211:51-76. doi: 10.1016/j.neuroscience.2011.10.057

43. Nicholas AP. Levodopa-induced hyperactivity in mice treated with 1methyl-4-phenyl-1,2,3,6-tetrahydropyridine. Mov Disord. (2007) 22:99-104. doi: $10.1002 / \mathrm{mds} .21235$

44. Lundblad M, Picconi B, Lindgren H, Cenci MA. A model of L-DOPAinduced dyskinesia in 6-hydroxydopamine lesioned mice: Relation to motor and cellular parameters of nigrostriatal function. Neurobiol Dis. (2004) 16:110-23. doi: 10.1016/j.nbd.2004.01.007

45. Lundblad $M$, Usiello A, Carta $M$, Hakansson $K$, Fisone G, Cenci MA. Pharmacological validation of a mouse model of L-DOPA-induced dyskinesia. Exp Neurol. (2005) 194:66-75. doi: 10.1016/j.expneurol.2005.02.002

46. Francardo V, Recchia A, Popovic N, Andersson D, Nissbrandt H, Cenci MA. Impact of the lesion procedure on the profiles of motor impairment and molecular responsiveness to L-DOPA in the 6-hydroxydopamine mouse model of Parkinson's disease. Neurobiol Dis. (2011) 42:327-40. doi: 10.1016/j.nbd.2011.01.024

47. Francardo V, Cenci MA. Investigating the molecular mechanisms of LDOPA-induced dyskinesia in the mouse. Parkinsonism Relat Disord. (2014) 20:S20-2. doi: 10.1016/S1353-8020(13)70008-7

48. Brooks SP, Dunnett SB. Tests to assess motor phenotype in mice: a user's guide. Nat Rev Neurosci. (2009) 10:519-29. doi: 10.1038/nrn2652

49. Lindgren HS, Rylander D, Ohlin KE, Lundblad M, Cenci MA. The "motor complication syndrome" in rats with 6-OHDA lesions treated chronically with L-DOPA: Relation to dose and route of administration. Behav Brain Res. (2007) 177:150-9. doi: 10.1016/j.bbr.2006.09.019

50. Monville C, Torres EM, Dunnett SB. Validation of the 1-dopa-induced dyskinesia in the 6-OHDA model and evaluation of the effects of selective dopamine receptor agonists and antagonists. Brain Res Bull. (2005) 68:16-23. doi: 10.1016/j.brainresbull.2004.10.011

51. Pavon N, Martin AB, Mendialdua A, Moratalla R. ERK phosphorylation and FosB expression are associated with L-DOPA-induced dyskinesia in hemiparkinsonian mice. Biol Psychiatry. (2006) 59:64-74. doi: 10.1016/j.biopsych.2005.05.044

52. Tekumalla PK, Calon F, Rahman Z, Birdi S, Rajput AH, Hornykiewicz O, et al. Elevated levels of DeltaFosB and RGS9 in striatum in Parkinson's disease. Biol Psychiatry. (2001) 50:813-6. doi: 10.1016/S0006-3223(01)01234-3

53. Lindgren HS, Rylander D, Iderberg H, Andersson M, O'Sullivan SS, Williams DR, et al. Putaminal upregulation of FosB/DeltaFosB-like immunoreactivity in Parkinson's disease patients with dyskinesia. J Parkinson's Dis. (2011) 1:347-57. doi: 10.3233/JPD-2011-11068

54. Berton O, Guigoni C, Li Q, Bioulac BH, Aubert I, Gross CE, et al. Striatal overexpression of DeltaJunD resets L-DOPA-induced dyskinesia in a primate model of Parkinson disease. Biol Psychiatry. (2009) 66:554-61. doi: 10.1016/j.biopsych.2009.04.005

55. Fasano S, Bezard E, D’Antoni A, Francardo V, Indrigo M, Qin L, et al. Inhibition of Ras-guanine nucleotide-releasing factor 1 (Ras-GRF1) 
signaling in the striatum reverts motor symptoms associated with Ldopa-induced dyskinesia. Proc Natl Acad Sci USA. (2010) 107:21824-9. doi: 10.1073/pnas.1012071107

56. Miller R, Beninger RJ. On the interpretation of asymmetries of posture and locomotion produced with dopamine agonists in animals with unilateral depletion of striatal dopamine. Prog Neurobiol. (1991) 36:229-56. doi: 10.1016/0301-0082(91)90032-V

57. Pycock CJ. Turning behaviour in animals. Neuroscience. (1980) 5:461-514. doi: 10.1016/0306-4522(80)90048-2

58. Schneider MB, Murrin LC, Pfeiffer RF, Deupree JD. Dopamine receptors: effects of chronic L-dopa and bromocriptine treatment in an animal model of Parkinson's disease. Clin Neuropharmacol. (1984) 7:247-57. doi: 10.1097/00002826-198409000-00006

59. Tsunekawa H, Takahata K, Okano M, Ishikawa T, Satoyoshi H, Nishimura $\mathrm{T}$, et al. Selegiline increases on time without exacerbation of dyskinesia in 6-hydroxydopamine-lesioned rats displaying L-Dopa-induced wearing-off and abnormal involuntary movements. Behav Brain Res. (2018) 347:350-9. doi: 10.1016/j.bbr.2018.03.002

60. Metz GA, Whishaw IQ. Drug-induced rotation intensity in unilateral dopamine-depleted rats is not correlated with end point or qualitative measures of forelimb or hindlimb motor performance. Neuroscience. (2002) 111:325-36. doi: 10.1016/S0306-4522(02)00013-1

61. Cenci MA, Crossman AR. Animal models of L-dopa-induced dyskinesia in Parkinson's disease. Mov Disord. (2018) 33:889-99. doi: 10.1002/mds.27337

62. Dupre KB, Eskow KL, Steiniger A, Klioueva A, Negron GE, Lormand L, et al. Effects of coincident 5-HT1A receptor stimulation and NMDA receptor antagonism on L-DOPA-induced dyskinesia and rotational behaviors in the hemi-parkinsonian rat. Psychopharmacology. (2008) 199:99-108. doi: 10.1007/s00213-008-1135-6

63. Pinna A, Pontis S, Morelli M. Expression of dyskinetic movements and turning behaviour in subchronic L-DOPA 6-hydroxydopamine-treated rats is influenced by the testing environment. Behav Brain Res. (2006) 171:175-8. doi: $10.1016 /$ j.bbr.2006.03.021

64. Morelli M, Fenu S, Pinna A, Cozzolino A, Carta A, Di Chiara G. "Priming" to dopamine agonist-induced contralateral turning as a model of non-associative sensitization to the expression of the post-synaptic dopamine message. Behav Pharmacol. (1993) 4:389-97. doi: 10.1097/00008877-199308000-00041

65. Einat $H$, Szechtman $H$. Environmental modulation of both locomotor response and locomotor sensitization to the dopamine agonist quinpirole. Behav Pharmacol. (1993) 4:399-403. doi: 10.1097/00008877-199308000-00013

66. Sullivan R, Dogaru C, Szechtman H. Constriction of environmental space and the behavioral response to the dopamine agonist quinpirole. Pharmacol Biochem Behav. (1992) 43:1217-9. doi: 10.1016/0091-3057(92)90505-A

67. Lee CS, Cenci MA, Schulzer M, Bjorklund A. Embryonic ventral mesencephalic grafts improve levodopa-induced dyskinesia in a rat model of Parkinson's disease. Brain. (2000) 123:1365-79. doi: 10.1093/brain/123.7.1365

68. Nutt JG. Levodopa-induced dyskinesia: review, observations, and speculations. Neurology. (1990) 40:340-5. doi: 10.1212/WNL.40.2.340

69. Cenci MA, Ohlin KE. Rodent models of treatment-induced motor complications in Parkinson's disease. Parkinsonism Relat Disord. (2009) 15 (Suppl. 4):S13-7. doi: 10.1016/S1353-8020(09)70828-4

70. Marin C, Jimenez A, Tolosa E, Bonastre M, Bove J. Bilateral subthalamic nucleus lesion reverses L-dopa-induced motor fluctuations and facilitates dyskinetic movements in hemiparkinsonian rats. Synapse. (2004) 51:140-50. doi: 10.1002/syn.10291

71. Cenci MA, Lundblad M. Ratings of L-DOPA-induced dyskinesia in the unilateral 6-OHDA lesion model of Parkinson's disease in rats and mice. Curr Protoc Neurosci. (2007) Chapter 9:Unit 925. doi: 10.1002/0471142301.ns0925s41

72. Shen H, Kannari K, Yamato H, Arai A, Matsunaga M. Effects of benserazide on L-DOPA-derived extracellular dopamine levels and aromatic L-amino acid decarboxylase activity in the striatum of 6-hydroxydopamine-lesioned rats. Tohoku J Exp Med. (2003) 199:149-59. doi: 10.1620/tjem.199.149

73. Morgese MG, Cassano T, Cuomo V, Giuffrida A. Anti-dyskinetic effects of cannabinoids in a rat model of Parkinson's disease: role of CB(1) and TRPV1 receptors. Exp Neurol. (2007) 208:110-9. doi: 10.1016/j.expneurol.2007.07.021

74. Kelsey JE, Neville C. The effects of the beta-lactam antibiotic, ceftriaxone, on forepaw stepping and L-DOPA-induced dyskinesia in a rodent model of Parkinson's disease. Psychopharmacology. (2014) 231:2405-15. doi: 10.1007/s00213-013-3400-6

75. Paul ML, Currie RW, Robertson HA. Priming of a D1 dopamine receptor behavioural response is dissociated from striatal immediate-early gene activity. Neuroscience. (1995) 66:347-59. doi: 10.1016/0306-4522(94)00582-P

76. Thiele SL, Warre R, Khademullah CS, Fahana N, Lo C, Lam D, et al. Generation of a model of L-DOPA-induced dyskinesia in two different mouse strains. J Neurosci Methods. (2011) 197:193-208. doi: 10.1016/j.jneumeth.2011.02.012

77. Bido S, Marti M, Morari M. Amantadine attenuates levodopainduced dyskinesia in mice and rats preventing the accompanying rise in nigral GABA levels. J Neurochem. (2011) 118:1043-55. doi: $10.1111 / j .1471-4159.2011 .07376 . x$

78. Lindenbach D, Conti MM, Ostock CY, George JA, Goldenberg AA, Melikhov-Sosin M, et al. The role of primary motor cortex (M1) glutamate and GABA signaling in L-DOPA-induced dyskinesia in parkinsonian rats. $J$ Neurosci. (2016) 36:9873-87. doi: 10.1523/JNEUROSCI.1318-16.2016

79. Maranis S, Stamatis D, Tsironis C, Konitsiotis S. Investigation of the antidyskinetic site of action of metabotropic and ionotropic glutamate receptor antagonists. Intracerebral infusions in 6-hydroxydopaminelesioned rats with levodopa-induced dyskinesia. Eur J Pharmacol. (2012) 683:71-7. doi: 10.1016/j.ejphar.2012.02.036

80. Azkona G, Sagarduy A, Aristieta A, Vazquez N, Zubillaga V, RuizOrtega JA, et al. Buspirone anti-dyskinetic effect is correlated with temporal normalization of dysregulated striatal DRD1 signalling in L-DOPA-treated rats. Neuropharmacology. (2014) 79:726-37. doi: 10.1016/j.neuropharm.2013.11.024

81. Bishop C, George JA, Buchta W, Goldenberg AA, Mohamed M, Dickinson SO, et al. Serotonin transporter inhibition attenuates LDOPA-induced dyskinesia without compromising L-DOPA efficacy in hemi-parkinsonian rats. Eur J Neurosci. (2012) 36:2839-48. doi: $10.1111 /$ j.1460-9568.2012.08202.x

82. Carta M, Carlsson T, Kirik D, Bjorklund A. Dopamine released from 5-HT terminals is the cause of L-DOPA-induced dyskinesia in parkinsonian rats. Brain. (2007) 130(Pt 7):1819-33. doi: 10.1093/brain/awm082

83. Iderberg H, Rylander D, Bimpisidis Z, Cenci MA. Modulating mGluR5 and $5-\mathrm{HT} 1 \mathrm{~A} / 1 \mathrm{~B}$ receptors to treat L-DOPA-induced dyskinesia: effects of combined treatment and possible mechanisms of action. Exp Neurol. (2013) 250:116-24. doi: 10.1016/j.expneurol.2013.09.003

84. Wang Q, Chen J, Li M, Lv S, Xie Z, Li N, et al. Eltoprazine prevents levodopa-induced dyskinesias by reducing causal interactions for theta oscillations in the dorsolateral striatum and substantia nigra pars reticulate. Neuropharmacology. (2019) 148:1-10. doi: 10.1016/j.neuropharm.2018.12.027

85. Jones N, Bleickardt C, Mullins D, Parker E, Hodgson R. A2A receptor antagonists do not induce dyskinesias in drug-naive or L-dopa sensitized rats. Brain Res Bull. (2013) 98:163-9. doi: 10.1016/j.brainresbull.2013.07.001

86. Lindenbach D, Ostock CY, Eskow Jaunarajs KL, Dupre KB, Barnum CJ, Bhide $\mathrm{N}$, et al. Behavioral and cellular modulation of L-DOPA-induced dyskinesia by beta-adrenoceptor blockade in the 6-hydroxydopamine-lesioned rat. $J$ Pharmacol Exp Ther. (2011) 337:755-65. doi: 10.1124/jpet.111.179416

87. Mango D, Bonito-Oliva A, Ledonne A, Cappellacci L, Petrelli R, Nistico $\mathrm{R}$, et al. Adenosine A1 receptor stimulation reduces D1 receptor-mediated GABAergic transmission from striato-nigral terminals and attenuates LDOPA-induced dyskinesia in dopamine-denervated mice. Exp Neurol. (2014) 261:733-43. doi: 10.1016/j.expneurol.2014.08.022

88. Shao YM, Ma X, Paira P, Tan A, Herr DR, Lim KL, et al. Discovery of indolylpiperazinylpyrimidines with dual-target profiles at adenosine A2A and dopamine D2 receptors for Parkinson's disease treatment. PLoS ONE. (2018) 13:e0188212. doi: 10.1371/journal.pone.0188212

89. Flores AJ, Bartlett MJ, Root BK, Parent KL, Heien ML, Porreca F, et al. The combination of the opioid glycopeptide MMP2200 and a NMDA receptor antagonist reduced L-DOPA-induced 
dyskinesia and MMP-2200 by itself reduced dopamine receptor 2-like agonist-induced dyskinesia. Neuropharmacology. (2018) 141:260-71. doi: 10.1016/j.neuropharm.2018.09.005

90. Thornton E, Hassall MM, Corrigan F, Vink R. The NK1 receptor antagonist $\mathrm{N}$-acetyl-L-tryptophan reduces dyskinesia in a hemiparkinsonian rodent model. Parkinsonism Rel Disord. (2014) 20:508-13. doi: 10.1016/j.parkreldis.2014.02.008

91. Yang X, Zhao H, Shi H, Wang X, Zhang S, Zhang Z, et al. Intranigral administration of substance $\mathrm{P}$ receptor antagonist attenuated levodopainduced dyskinesia in a rat model of Parkinson's disease. Exp Neurol. (2015) 271:168-74. doi: 10.1016/j.expneurol.2015.05.007

92. Marti M, Rodi D, Li Q, Guerrini R, Fasano S, Morella I, et al. Nociceptin/orphanin FQ receptor agonists attenuate LDOPA-induced dyskinesias. J Neurosci. (2012) 32:16106-19. doi: 10.1523/JNEUROSCI.6408-11.2012

93. Solis O, Espadas I, Del-Bel EA, Moratalla R. Nitric oxide synthase inhibition decreases L-DOPA-induced dyskinesia and the expression of striatal molecular markers in Pitx3(-/-) aphakia mice. Neurobiol Dis. (2015) 73:49-59. doi: 10.1016/j.nbd.2014.09.010

94. Bordia T, Campos C, Huang L, Quik M. Continuous and intermittent nicotine treatment reduces L-3,4-dihydroxyphenylalanine (L-DOPA)induced dyskinesias in a rat model of Parkinson's disease. J Pharmacol Exp Ther. (2008) 327:239-47. doi: 10.1124/jpet.108.140897

95. Bordia T, Campos C, McIntosh JM, Quik M. Nicotinic receptor-mediated reduction in L-DOPA-induced dyskinesias may occur via desensitization. $J$ Pharmacol Exp Ther. (2010) 333:929-38. doi: 10.1124/jpet.109.162396

96. Huang LZ, Campos C, Ly J, Ivy Carroll F, Quik M. Nicotinic receptor agonists decrease L-dopa-induced dyskinesias most effectively in partially lesioned parkinsonian rats. Neuropharmacology. (2011) 60:861-8. doi: 10.1016/j.neuropharm.2010.12.032

97. Huang LZ, Grady SR, Quik M. Nicotine reduces L-DOPA-induced dyskinesias by acting at beta2* nicotinic receptors. J Pharmacol Exp Ther. (2011) 338:932-41. doi: 10.1124/jpet.111.182949

98. Zhang D, McGregor M, Bordia T, Perez XA, McIntosh JM, Decker MW, et al. $\alpha 7$ nicotinic receptor agonists reduce levodopa-induced dyskinesias with severe nigrostriatal damage. Mov Disord. (2015) 30:1901-11. doi: $10.1002 / \mathrm{mds} .26453$

99. Sander SE, Lemm C, Lange N, Hamann M, Richter A. Retigabine, a $\mathrm{K}(\mathrm{V}) 7$ (KCNQ) potassium channel opener, attenuates L-DOPAinduced dyskinesias in 6-OHDA-lesioned rats. Neuropharmacology. (2012) 62:1052-61. doi: 10.1016/j.neuropharm.2011.10.016

100. Gonzalez-Aparicio R, Moratalla R. Oleoylethanolamide reduces L-DOPAinduced dyskinesia via TRPV1 receptor in a mouse model of Parkinson's disease. Neurobiol Dis. (2014) 62:416-25. doi: 10.1016/j.nbd.2013.10.008

101. Santini E, Valjent E, Usiello A, Carta M, Borgkvist A, Girault JA, et al. Critical involvement of cAMP/DARPP-32 and extracellular signal-regulated protein kinase signaling in L-DOPA-induced dyskinesia. J Neurosci. (2007) 27:6995-7005. doi: 10.1523/JNEUROSCI.0852-07.2007

102. Santini E, Valjent E, Fisone G. mTORC1 signaling in Parkinson's disease and L-DOPA-induced dyskinesia: a sensitized matter. Cell Cycle. (2010) 9:2713-8. doi: $10.4161 /$ cc.9.14.12180

103. Santini E, Feyder M, Gangarossa G, Bateup HS, Greengard P, Fisone G. Dopamine- and cAMP-regulated phosphoprotein of $32-\mathrm{kDa}$ (DARPP32)-dependent activation of extracellular signal-regulated kinase (ERK) and mammalian target of rapamycin complex 1 (mTORC1) signaling in experimental parkinsonism. J Biol Chem. (2012) 287:27806-12. doi: 10.1074/jbc.M112.388413

104. Borgkvist A, Lieberman OJ, Sulzer D. Synaptic plasticity may underlie L-DOPA induced dyskinesia. Curr Opin Neurobiol. (2018) 48:71-8. doi: 10.1016/j.conb.2017.10.021

105. Picconi B, De Leonibus E, Calabresi P. Synaptic plasticity and levodopainduced dyskinesia: Electrophysiological and structural abnormalities. $J$ Neural Transm. (2018) 125:1263-71. doi: 10.1007/s00702-018-1864-6

106. Thiele SL, Chen B, Lo C, Gertler TS, Warre R, Surmeier JD, et al. Selective loss of bi-directional synaptic plasticity in the direct and indirect striatal output pathways accompanies generation of parkinsonism and L-DOPA induced dyskinesia in mouse models. Neurobiol Dis. (2014) 71:334-44. doi: 10.1016/j.nbd.2014.08.006
107. Shen W, Plotkin JL, Francardo V, Ko WK, Xie Z, Li Q, et al. M4 Muscarinic receptor signaling ameliorates striatal plasticity deficits in models of L-DOPA-induced dyskinesia. Neuron. (2015) 88:762-73. doi: 10.1016/j.neuron.2015.10.039

108. Brugnoli A, Napolitano F, Usiello A, Morari M. Genetic deletion of Rhes or pharmacological blockade of mTORC1 prevent striato-nigral neurons activation in levodopa-induced dyskinesia. Neurobiol Dis. (2016) 85:155-63. doi: 10.1016/j.nbd.2015.10.020

109. Martin-Flores N, Fernandez-Santiago R, Antonelli F, Cerquera C, Moreno V, Marti MJ, et al. MTOR pathway-based discovery of genetic susceptibility to L-DOPA-induced dyskinesia in Parkinson's disease patients. Mol Neurobiol. (2019) 56:2092-100. doi: 10.1007/s12035-018-1219-1

110. Cerovic M, Bagetta V, Pendolino V, Ghiglieri V, Fasano S, Morella I, et al. Derangement of Ras-guanine nucleotide-releasing factor 1 (RasGRF1) and extracellular signal-regulated kinase (ERK) dependent striatal plasticity in L-DOPA-induced dyskinesia. Biol Psychiatry. (2015) 77:106-15. doi: 10.1016/j.biopsych.2014.04.002

111. Ruiz-DeDiego I, Fasano S, Solis O, Garcia-Montes JR, Brea J, Loza MI, et al. Genetic enhancement of Ras-ERK pathway does not aggravate LDOPA-induced dyskinesia in mice but prevents the decrease induced by lovastatin. Sci Rep. (2018) 8:15381. doi: 10.1038/s41598-018-33 713-3

112. Nicoletti F, Bockaert J, Collingridge GL, Conn PJ, Ferraguti F, Schoepp DD, et al. Metabotropic glutamate receptors: from the workbench to the bedside. Neuropharmacology. (2011) 60:1017-41. doi: 10.1016/j.neuropharm.2010.10.022

113. Pourmirbabaei S, Dolatshahi M, Rahmani F. Pathophysiological clues to therapeutic applications of glutamate mGlu5 receptor antagonists in levodopa-induced dyskinesia. Eur J Pharmacol. (2019) 855:149-59. doi: 10.1016/j.ejphar.2019.05.004

114. Li Q, Ke Y, Chan DC, Qian ZM, Yung KK, Ko H, et al. Therapeutic deep brain stimulation in Parkinsonian rats directly influences motor cortex. Neuron. (2012) 76:1030-41. doi: 10.1016/j.neuron.2012.09.032

115. McCarthy MM, Moore-Kochlacs C, Gu X, Boyden ES, Han X, Kopell N. Striatal origin of the pathologic beta oscillations in Parkinson's disease. Proc Natl Acad Sci USA. (2011) 108:11620-5. doi: 10.1073/pnas.11077 48108

116. Dupre KB, Cruz AV, McCoy AJ, Delaville C, Gerber CM, Eyring KW, et al. Effects of L-dopa priming on cortical high beta and high gamma oscillatory activity in a rodent model of Parkinson's disease. Neurobiol Dis. (2016) 86:1-15. doi: 10.1016/j.nbd.2015.11.009

117. Halje P, Tamte M, Richter U, Mohammed M, Cenci MA, Petersson P. Levodopa-induced dyskinesia is strongly associated with resonant cortical oscillations. J Neurosci. (2012) 32:16541-51. doi: 10.1523/JNEUROSCI.3047-12.2012

118. Paille V, Henry V, Lescaudron L, Brachet P, Damier P. Rat model of Parkinson's disease with bilateral motor abnormalities, reversible with levodopa, and dyskinesias. Mov Disord. (2007) 22:533-9. doi: $10.1002 / \mathrm{mds} .21308$

119. Marin C, Bonastre M, Mengod G, Cortes R, Rodriguez-Oroz MC. From unilateral to bilateral parkinsonism: effects of lateralization on dyskinesias and associated molecular mechanisms. Neuropharmacology. (2015) 97:365-75. doi: 10.1016/j.neuropharm.2015.06.004

120. Morin N, Jourdain VA, Di Paolo T. Modeling dyskinesia in animal models of Parkinson disease. Exp Neurol. (2014) 256:105-16. doi: 10.1016/j.expneurol.2013.01.024

121. Creed RB, Goldberg MS. New developments in genetic rat models of Parkinson's disease. Mov Disord. (2018) 33:717-29. doi: 10.1002/mds.27296

122. Kovoor A, Seyffarth P, Ebert J, Barghshoon S, Chen CK, Schwarz S, et al. D2 dopamine receptors colocalize regulator of G-protein signaling 9-2 (RGS9-2) via the RGS9 DEP domain, and RGS9 knock-out mice develop dyskinesias associated with dopamine pathways. J Neurosci. (2005) 25:2157-65. doi: 10.1523/JNEUROSCI.2840-04.2005

123. Terzioglu M, Galter D. Parkinson's disease: Genetic versus toxin-induced rodent models. FEBS J. (2008) 275:1384-91. doi: 10.1111/j.1742-4658.2008.06302.x

124. Ding Y, Won L, Britt JP, Lim SA, McGehee DS, Kang UJ. Enhanced striatal cholinergic neuronal activity mediates L-DOPA-induced dyskinesia 
in parkinsonian mice. Proc Natl Acad Sci USA. (2011) 108:840-5. doi: 10.1073/pnas.1006511108

125. Cao X, Yasuda T, Uthayathas $\mathrm{S}$, Watts RL, Mouradian MM, Mochizuki $\mathrm{H}$, et al. Striatal overexpression of DeltaFosB reproduces chronic levodopa-induced involuntary movements. J Neurosci. (2010) 30:7335-43. doi: 10.1523/JNEUROSCI.025210.2010

126. Feyder M, Sodersten E, Santini E, Vialou V, LaPlant Q, Watts EL, et al. A role for mitogen- and stress-activated kinase 1 in L-DOPAinduced dyskinesia and FosB expression. Biol Psychiatry. (2016) 79:362-71. doi: 10.1016/j.biopsych.2014.07.019
Conflict of Interest: The authors declare that the research was conducted in the absence of any commercial or financial relationships that could be construed as a potential conflict of interest.

Copyright (๑) 2019 Peng, Zhong, Tan, Zeng, Wang, Cheng, Yang, Wu, Cao and Xu. This is an open-access article distributed under the terms of the Creative Commons Attribution License (CC BY). The use, distribution or reproduction in other forums is permitted, provided the original author $(s)$ and the copyright owner(s) are credited and that the original publication in this journal is cited, in accordance with accepted academic practice. No use, distribution or reproduction is permitted which does not comply with these terms. 